\title{
Making gains: the impact of outdoor residential experiences on students' examination grades and self-efficacy
}

Article

Accepted Version

Fuller, C., Powell, D. and Fox, S. (2017) Making gains: the impact of outdoor residential experiences on students' examination grades and self-efficacy. Educational Review, 69 (2). pp. 232-247. ISSN 1465-3397 doi:

https://doi.org/10.1080/00131911.2016.1199538 Available at https://centaur.reading.ac.uk/65777/

It is advisable to refer to the publisher's version if you intend to cite from the work. See Guidance on citing.

To link to this article DOI: http://dx.doi.org/10.1080/00131911.2016.1199538

Publisher: Routledge

All outputs in CentAUR are protected by Intellectual Property Rights law, including copyright law. Copyright and IPR is retained by the creators or other copyright holders. Terms and conditions for use of this material are defined in the End User Agreement.

www.reading.ac.uk/centaur 
Central Archive at the University of Reading

Reading's research outputs online 
Making Gains: the impact of outdoor residential experiences on students' examination grades and self-efficacy

Dr Carol Fuller* Institute of Education, University of Reading, 4 Redlands Road, Reading, Berkshire, UK, RG1 5EX c.l.fuller@ reading.ac.uk Tel: 01183782662

Dr Daisy Powell Institute of Education, University of Reading, 4 Redlands Road, Reading, Berkshire, UK, RG1 5EX d.a.powell@ reading.ac.uk Tel: 01183782797

Mr Simon Fox, The University of Reading Institute of Education, University of Reading, 4 Redlands Road, Reading, Berkshire, UK, RG1 5EX s.j.fox@student.reading.ac.uk Tel: 0118 3782662

*Corresponding author, Institute of Education, University of Reading, 4 Redlands Road, Reading, Berkshire, UK, RG15EX c.l.fuller@reading.ac.uk

This research was carried out at the University of Reading 


\begin{abstract}
In this paper we explore the role of outdoor residential experiences on the sense of efficacy and examination attainment of a group of under achieving students from socially disadvantaged backgrounds. The paper reports on a three year project which focuses on two groups of year nine (age 14) to year eleven (age 16) students. The results reported here strongly suggest that the impact of these visits has been significant in terms of students' sense of confidence and efficacy and had a statistically significant impact on formal examination results in school. We conclude by suggesting that outdoor residential experiences have real educational value for those that take part and, given the evidence provided, believe this poses an interesting question as to whether the classroom should remain the primary site of learning because of the ways it develops positive outcomes within school.
\end{abstract}

Keywords: efficacy, grades, residential; social background

\title{
Acknowledgements
}

In carrying out this research the authors would like to thank Professor Suzanne Graham for her support and guidance as well as the Society for Educational Studies for funding. The authors are also grateful to all the students included, the school and the school staff as well as the outdoor educationalists and educational trust that facilitate and provide the opportunities that make this research possible.

\section{Introduction}

Children from the poorest and least advantaged families still significantly underachieve in education in the UK today, in spite of the best efforts of policy makers and educationalists to promote greater parity in terms of educational outcomes. For example, in 2009 only $27 \%$ of young people eligible for Free School Meals ${ }^{1}$ achieved 5 or more high level grades $\left(A^{*}-\mathrm{C}\right)$ in the examinations taken at age 16 in England, the General Certificate of Secondary Education (GCSE), compared to 54\% of non-eligible students (Office of National Statistics 2012).

Children from poorer socio-economic groups are also less likely to continue with education post-16, enter higher education and are more likely than any other group to end up Not in Education, Employment or Training (NEET). As educational outcomes link so fundamentally to future life course outcomes (see www.poverty.org.uk for example), this persisting inequality remains an area of priority and concern yet the success of a number of

\footnotetext{
${ }^{1}$ Free School Meals is a measure of social deprivation in the UK
} 
policy initiatives aimed at 'closing the gap' are largely seen to have been minimal (Ker and West 2010). This is also underlined by the findings of a very recent report commissioned by the National Children's Bureau (2013) that educational outcomes for economically disadvantaged children have not improved since the 1960s, and indeed in some instances, have become worse. The report highlights that even after more than 50 years of measures to improve outcomes, children from the most deprived areas are still less likely to do as well in their GCSEs at 16 as their peers.

\section{Background}

Despite the limited success of a range of policy initiatives and interventions, raising the educational attainment of society's least advantaged remains a significant priority concern for government and policy makers across a range of global contexts, not least because educational attainment links so directly to life course outcomes as well as a nation's economy overall. For example, across all Organisation for Economic Co-operation and Development (OECD) countries, employment rates are much higher for those with a further education, than for those without (OECD 2012). In addition, within the UK, a student who undertakes an undergraduate degree can expect to earn, on average, $27.4 \%$ more than a student with two or more General Certificate of Education 'A' levels (Conlon and Patrignani 2011), the qualification taken at 18 years in England. As earnings link so significantly with quality of life, remaining in post-compulsory education or training is therefore important. Improving educational attainment rates also has other social benefits such as reducing crime levels (Machin, Marie and Vujic 2010); improvements in health (Furnee, Groot, Maassen van der Brink 2008) as well as reducing teenage pregnancy (Teenage Pregnancy Associates, 2011) and dependency on social funding. Nevertheless, students from poorer socioeconomic backgrounds are least likely to remain in post-compulsory education or move into higher education and this issue remains a concern in most western countries.

The reasons behind differential attainment are complex. A comprehensive review of current research carried out in the UK by the Joseph Rowntree Foundation suggests that, among other things, attitudes to education and ambitions for further education were key factors in understanding and explaining the phenomenon. The review found that recognition of the value of learning and a sense of self efficacy via a belief in ability to achieve was fundamental to improving rates of attainment and ambitions (Goodman and Gregg 2010). Similar findings were also reflected in a large scale ESRC-funded study on young peoples' 
perspectives on the value of education within England (Croll, Attwood and Fuller 2010). The research found that a student's attitude to school and learning was significant in explaining post-16 educational intentions. How students identify themselves as learners, in terms of their confidence to achieve educationally and in terms of their future career ambitions was also found to be key in explaining the educational aspirations and outcomes of a group of socially disadvantaged girls (Fuller 2009; 2013). Attitudes towards education and future educational and career aspirations were not directly related to actual attainment or potential to attain but were the result of a student's own understanding of her chances of success.

Research also suggests, however, that raising the aspirations of lower income students alone does not promote improving educational attainment (Carter-Wall and Whitefield 2012). Indeed, many of today's teenagers are highly ambitious (Croll et al 2010; Croll, Attwood, Fuller and Last 2008). Yet there can often be a misalignment between aspirations and the educational attainment required to achieve these goals, with some students both over and under estimating their likelihood of success (Schneider and Stevenson 1999; Sabates, Harris and Staff 2011). Research also suggests that young people with lower prior achievement and from lower socioeconomic backgrounds are those who were much more likely to have uncertainty about their future career plans (Gutman and Schoon 2012). Furthermore, as outlined above, confidence in an ability to succeed, alongside a belief in the value of educational engagement is also important (Fuller 2013; Fuller and Macfadyen 2012), supporting the view that a sense of self-efficacy is an important driver for motivation to learn.

Yet the development of such confidence is also a complex process. Furthermore, young people draw on a number of frameworks when making their post- compulsory educational choices, not least an understanding of a changing and competitive labour market in which education and skills are central. For a number of young people some educational choices are perceived as involving much greater risk than others, particularly regarding future employment security (Beck 1992). The 'likelihood of success' is also an important feature in choices (Goldthorpe 1996) and significantly influential when weighing up the costs and benefits of the various educational routes available to them. In a theoretical sense, students from less socially advantaged backgrounds are understood to be risk adverse when making future educational and career choices; weighing up the choices available and evaluating their options based on an understanding of their likelihood of succeeding (Boudon 1974; Goldthorpe 1996; Goldthorpe \& Breen 2000). Typically, for students from poorer 
backgrounds, choices are often also situated within culturally determined horizons. This means that aspirations and ambitions are primarily mediated through structured social spaces, with choices and goals reflecting young peoples' current experiences of their social and occupational location (Hodkinson 2008), i.e. the choices, goals and occupations of families, friends and neighbourhood. This also relates to ideas from other theoretical frameworks and from other perspectives, e.g. to the social cognitive theory of Bandura (e.g. 1995), where selfefficacy, i.e. the belief in one's ability to succeed in specific endeavours, is in part influenced by 'seeing people similar to themselves succeed' alongside 'mastery experiences' (emphasis in the original), i.e. those that provide 'experience in overcoming obstacles through perseverant effort' (Bandura 1995:7).

Whilst looking at ways that experience and structure impacts on education, it is also important to consider the ways that young people reflectively make sense of themselves within the field of education. Self-identification, particularly as it relates to a person perception of themselves as someone who succeeds educationally or not, is also important to understanding confidence and efficacy. As Fuller notes, $(2009 ; 2014)$ trust in the ability to achieve is important in identity construction within education and has a direct impact on educational engagement and ambitions. Berger and Luckmann's (1966) seminal work consider the ways that social reality is created and embedded through social interactions and individual interpretations of these. This paper draws on these ideas, to provide a theoretical framework for this study i.e. that whilst social structure may predict student outcomes, in terms of reproducing social positions, individuals are also reflective and rational and are therefore able to redefine and renegotiate predicted life course outcomes. It is also held that the self-efficacy beliefs of individuals are amenable to change and that whilst outdoor residential experiences may increase a sense of efficacy in that specific domain, it may well be that students can reflect on these experiences and connect them to the school setting.

Recent government initiatives in England to address the persistent underachievement and lower post-compulsory education aspirations of socially disadvantaged young people do not clearly take account of such explanations for these phenomena. For example, the UK government introduced the Pupil Premium in 2011. This is a payment, additional to main school funding, designed to address the current underlying inequalities between children eligible for free school meals (FSM) and their peers. The premise underlying its introduction 
is that by ensuring that funding to tackle disadvantage reaches the pupils who need it most, educational attainment and aspirations will be raised. Schools receive a significant premium payment ( $£ 900$ in 2014) for each child registered for FSM - either currently registered and in receipt or, registered previously (within the last 6 years). Schools have autonomy in deciding how to use funding and it can be used in any number of ways, for example, to support additional tutoring, to buy in additional equipment, for example, lap top computers or, used to support extra-curricular activities. The onus on attainment is clear however and the UK government is unequivocal regarding the accountability of schools in needing to demonstrate clear progress in attainment for these students if they are to maintain their funding. Arguably, this focus on attainment alone will not necessarily address lower educational achievement and aspirations, unless it is also coupled with measures that target specifically the development of young people's confidence and sense of educational self-efficacy.

By providing learners with opportunities for 'mastery experiences' (Bandura 1995:7), the extra-curricular activities that the Pupil Premium can fund might potentially aid the development of such confidence, but as yet the evidence for the benefits of this type of activity is mixed, making it risky for schools to invest Pupil Premium in such a way. There are a number of studies that link out-of-school activities with the building of self-confidence and pro-social and educational behaviour (Hirch 2007; Standford, Armoura and Warnington 2006) as well as positive consequences in attainment (Randall, 2013). Research also suggests that outdoor learning provision can result in positive development and can support the curriculum very specifically (Christie, B., Higgins, P. and McLaughlin 2014). Positive influences are also indicated for learning, engagement and educational outcomes more broadly (Bentsen, Mygind and Randrup 2009; Wikeley, Bullock, Muschamp and Ridge 2000).

Looking more specifically at outdoor activities, there is an indication that these can have benefits for young peoples' practical skills, sense of efficacy and confidence etc. (Dillon et al 2004; Waite 2010). Research by Hattie, Marsh, Neill and Richards (1997) found an overall improvement rate in student learning from outdoor adventurous activities. In a meta-analysis of ninety six studies they found that the effect of a range of experiences was significant and that participants made substantial gains in a number of areas. However, they also stated that 
not enough was known as to why these programmes worked. In addition, whilst Hattie (2015) acknowledges that the teacher is central to wherever learning is happening, policy tends to focus on between school variations in attainment and not ways to intervene and support learning. This means that how outdoor learning experiences may support educational outcomes or not, will not be a focus of interest to policy makers. Other studies also suggest that out-of-school activities can significantly help to build self-confidence and pro-social and educational behaviour (Hirch 2007; Standford, Armoura and Warnington 2006).

Residential experiences are a useful way of providing opportunity to foster new relationships because they allow time, space and intensity of experience (Paul Hamlyn Foundation 2014). Benston et al (2009) usefully contextualise the value of education outside of the classroom via a synthesis of Danish research in this area. They consider the range and type of activities and do so within the context of international interest in the area and the universality of the programmes offered. They conclude by proposing that a range of evidence suggests that 'normal' classroom learning, in conjunction with outdoor experiences, is highly beneficial to learners, particularly with respect to social and psychological well-being and health.

Waite (2013) explores the value of the relationships that develop with both adults and peers when learning outside of the classroom. Whilst place is clearly important, for Waite, it was the relationships that developed with the teachers and pupils and the skills developed that were more important than the location itself. Arguably, residential experiences allow for the time required for these relationships to develop. A final report for the Paul Hamlyn Foundation on Learning Away (2015) also illustrates the ways that the development of deeper relationships, cohesion and belonging had important consequences for young people and their confidence. They highlight how teachers and students learning together breaks down status barriers and positions everyone on the same level. Strengthening relationships promotes trust and sense of community that promotes the engagement and confidence that is important.

Despite the many positive benefits identified, a key finding nevertheless, is that it is children from advantaged backgrounds who tend to have the access to these sorts of outdoor activities (Hirch 2007). Rather surprisingly, research on the direct impact of outdoor experiences on 
the educational confidence of socially disadvantaged students and its transference into the classroom is almost non-existent. Furthermore, other investigations into the impact of outdoor activities present much more mixed and weaker evidence for their benefits (Rickinson et al 2004). In a review of literature in the UK this area, Carter-Wall and Whitefield (2012) found that there was mixed evidence on the impact of interventions focused on extra-curricular activities and the development of children's self-belief and motivation. They therefore recommended that outdoor learning should be developed and evaluated further and that a particular focus on the impact on children's general attitudes to education is important. These views are also echoed by a number of authors including Christie et al. (2014) and are reiterated in an Education and Skills Select Committee Enquiry (2005) on Education Outside of the Classroom within the UK/England, and by a report on Outdoor Education by the UK Office for Standards in Education (OfSted 2004). The reports indicate that much greater empirical and conceptual understanding of the ways that learning outside of the classroom can benefit the learner is needed. Primarily, many of the studies in this area have tended to look at the short term impact of outdoor experiences as opposed to the longer terms benefits that are more readily captured through longitudinal research.

It is important to make clear that this paper does not consider the role of outdoor education theory, curriculum or assessment in outdoor learning experiences but does recognise that this is an important consideration. Instead, given the paucity of research into the impact of outdoor experiences within school, it seeks to report on the findings of a three year study that explores the potential value of outdoor residential experiences. Specifically, the paper considers the ways that students articulate their sense of self-confidence, in terms of the ways they see the impact of their residential experiences expressed in school and in their learning as well as their actual attainment in the GCSE exams. The research questions addressed by this paper are therefore:

1. What is the impact of residential experiences on students' perception of their selfefficacy in school?

2. What is the impact of residential experiences on students' performance in their GCSE exams in school? 


\section{Research design}

To track change on perceptions of efficacy and impact on exam grades, the research design for this three year study was a mixed methods, intervention, case study. Limitations of previous research in this area are the cross-sectional nature of the research design for research that tends to look at impact. There is also a lack of quasi/experimental, longitudinal research (Fiennes, Oliver, Dickson, Escobar, Romans and Oliver, 2015) In this study, the research is therefore also longitudinal. This design was selected so as to optimise the depth of data collected.

In this study the concept of efficacy is understood to be young peoples' beliefs in relation to their ability to succeed at something, that is, a sense of trust in their abilities. Self-efficacy is important to confidence in education as trusting in an ability to do something, such as learn or to achieve well in an exam, will impact on a person's desire and ambition to try something, rather than avoid it, as is arguably the case in educational disengagement.

\section{The sample}

The research focused on two groups of year nine students (age 14 years), who were followed until the end of year 11 (age 16). Year nine students were selected as this was considered a significant year in a student's life as the time when they have to make their GCSE exam choices. The research comprised a group of 12 students as well as a control group of 12 students. The two groups were matched for gender and as far as possible, for FSM, ethnicity and actual and predicted levels of attainment, i.e. on the target for $5 \mathrm{~A}^{*}$-C at GCSE, as well as attainment in the core subjects of English, Maths and Science. Whilst students were not matched perfectly in these three core subjects, they were matched as closely as possible in terms of whether they were underachieving in one, two or three subject areas. Students were matched on a case by case basis and were selected from an anonymised data set for the whole year eight (age 13) student group, provided by the school. The study sought to capture the full range of potential educational impacts of residential outdoor experiences, and so tracked the two groups of students over a period of three years: the research group, who took part in twice yearly, three day residential visits and a control group that did not. This paper reports on the qualitative data from the research group as well as the final exam grades for both the research and control group. 
In terms of the process for selecting individual students, amid a context of under-attainment, funding was available for 15 students. To select those students who were to participate, all students in the year group were initially assigned an ID number, the research group were selected on the basis of being the first 15 students identified as under attaining.. A control group was then selected after the research group had been chosen and from the same anonymised data set). In terms of the control, these remained anonymous; attainment data was used from students in the control but these students were not interviewed. This was to ensure that students in the control were not identified or at any particular disadvantage in the context of the whole year group ${ }^{2}$. It is worth noting that the researchers in the study are academics and had no connections to the school, the students or the field of outdoor/residential learning. In this sense, we came to the research very much as 'outsiders'.

\section{The Participants}

Information relevant to this sample appears in Table 1 below. As can be seen both the research and control groups comprised 12 students; nine boys and three girls each. All 24 students (12 in each group) were from manual or unemployed households. Social economic status was determined either by the recording of parental occupation and/or whether a student was in receipt of Free School Meals or Pupil Premium. Whilst none of these are perfect measure, they are reasonable when attempting to establish SES when considered in conjunction with the contextual data for the school. For 8 of the students in the research group, the school were in receipt of Pupil Premium (PP) funding, whilst this was true for only 5 from the control group by the end of the study. 3 students in each group had English as a Second Language (ESL).

Table 1 - Information on sample here

\footnotetext{
${ }^{2}$ It is worth noting that as a direct result of this research, more schools have opted to undertake a similar programme, with bigger student numbers and from year seven
} 


\section{Methods of data collection}

As the research is interested in meaning making and the role that experiences and reflective understandings have on efficacy and actual exam grade outcomes, exploring these through the eyes of the students as well as via school data was important. The impact of visits was explored though one to one interviews with the research group. Three rounds of interviews which lasted around 30 minutes were carried out in between residential visits, in school, with all participants in the research group. Interviews explored a range of areas including attitudes to school and learning, future ambitions and the residential experiences. In addition, how students saw themselves as students and how these perceptions changed over time were also explored

Students took part in two visits a year across the three years, arriving at the centre on a Friday afternoon and returning home on Sunday evening. The participation in a number of residential weekends permitted the employment of additional qualitative data collection methods: participant observations, which focused on behaviour and interactions, and more unstructured interviews, with respect to participation in the activities being undertaken, for example, as well as during leisure time during the weekends. Attainment data was collected prior to the start of the study and provided the baseline for grades, in that they provided the starting point prior to the intervention. Data was then collected again at the end of year 11. Data collected included all GCSE examination results, as well as the Attainment 8 (Progress 8) score for each student. Attainment 8 measures relate to the achievement of a pupil across 8 subjects including mathematics (double weighted) and English (double weighted), 3 further qualifications that count in the English Baccalaureate measure (such as languages and humanities subjects) and 3 further qualifications that can be GCSE qualifications (including English Baccalaureate subjects) or any other non-GCSE qualifications on the DfE approved list (DfE 2015). The Attainment 8 Expected and Actual Grades are then calculated. 


\section{The Case Study School}

The research is carried out with students attending an academy school in the South East of England. The school itself is situated in an area of high social deprivation and is the most deprived area locally. $54 \%$ of its student population is considered disadvantaged and the school is positioned within the top $5 \%$ of areas most deprived nationally for education, skills and training. In the 2012/13 destination survey for the school, no student was recorded in higher education. In February 2012 the school was placed onto Special Measures, an outcome applied by the OfSTED inspectorate of schools to those schools deemed to be failing, particularly with respect to standards in teaching and learning. The research began in the summer 2013, after the school was placed on Special Measures. The school was removed from this category in Spring 2014 and then replaced onto Special Measures in January 2016. In the year that the students in this research took their GCSE exams, only $26 \%$ of the 171 year 11 cohort achieved $5 \mathrm{~A}^{*}-\mathrm{C}$ (a recognised measure of attainment in England and Wales at the time of this research), compared to 57\% locally and 54\% nationally (DfEa 2015).

\section{The Outdoor Residential Centre}

The outdoor centre is located in the countryside. Although geographically not very far, it is strikingly different to the locale of the school. Log cabins sit within rolling landscape and dense woodland, just a few metres away from an impressive Tudor mansion, The centre was developed through a partnership between an associated Educational Trust and the neighbourhood in which the case study school is situated. Focusing in particular on schools in neighbourhoods of high social disadvantage, it provides a range of outdoor residential experiences in a location which is rural, being situated within a large woodland landscape, yet not at too great a distance to the homes and schools of the students who attend.

For the purpose of this study students take part in a range of programmes that had been designed specifically for the research. The programme includes activities such as woodland archery, canoeing, mountain biking and making a fire amongst other things and also provided opportunity for self-reflection and team building skills. In terms of content, programmes were designed specifically prior to each weekend, and were developed in conjunction with the 
outdoor specialists, the school and the researchers. The programmes were designed specifically for the research and focused on a range of skills such as team building, problem solving and communication as well providing opportunities for reflection and to develop softer social skills. The idea was to provide activities and experiences that would enable students to develop confidence, resilience and a sense of efficacy. The repeated nature of the programme was therefore important to enable the building and strengthening of skills in these areas. Hence, many of the activities were repeated throughout the course of the research.

The research emerged from a desire to study the benefits of what is offered by the centre more empirically. The centre had a well-established relationship, developed over many years, with the local area and with the school. The programme was delivered by qualified outdoor educationalists and students were accompanied on the residential trips by a range of teaching staff from their school. It is worth noting that the programme was delivered over a weekend and therefore depended on staff from across the curriculum areas volunteering to accompany students. This meant that it was unusual for the same member of staff to accompany students twice.

\section{Data analysis}

All school attainment data was explored in relation to the actual against predicted grades in GCSE English, Maths and Science as well as the scores for expected and actual Attainment 8 measures (Progress 8). Grades at GCSE for English, maths and science were converted to a numerical value, using the UK government points based equivalency scales (DfE 2011). An independent samples t-test, a suitable test when the sample size is small, was then used to explore the statistical relationship between the predicted and achieved grades of students in the research and control group. A t-test ${ }^{3}$ was used to explore whether any differences between the groups' final exam grades was likely to be the result of chance. Observed differences are considered meaningful only when the difference between averages is large but the standard

\footnotetext{
${ }^{3}$ Given the small sample size, results of the $t$ test were verified by carrying out a non-parametric equivalent (Mann-Witney $\mathrm{U}$ ) which produced the same result.
} 
deviation is low. The t-test provides two outputs: one which relates to the statistical significance of any differences between the samples as well as the effect size.

Initial data screening identified two students in both the research and control groups who had done unexpectedly well and were thus identified as statistical outliers. These were therefore removed from the analysis. However, results in the following section will show that there remained statistically significant attainment gains for the research group with and without the outliers.

All interviews were recorded and transcribed. Data were coded using an inductive/deductive analytical approach, drawing on themes identified in the literature as well as those emerging through the process of a constant comparative, iterative approach. This combined procedure proved highly useful as themes not previously considered in the literature emerged as areas of importance and significance, for example, 'friendships'. All qualitative data was initially loosely coded to identify the key organisational themes. Following on from this first stage thematic analysis, codes within each of the key themes were then identified. For the purposes of this paper, narrative associated with the theme of 'efficacy' is addressed. Within this theme, codes connected to 'efficacy' as it related to 'home', 'school', 'friendship' and 'experiences' are explored.

In carrying out this research, all University ethical guidelines were complied with. In this research, this relates primarily to the informed consent of all those taking part in the research. In reporting the findings, no real names are used.

\section{Findings}

We address both of our research questions below: 


\section{What is the impact of residential experiences on students' performance in their GCSE exams in school?}

\section{Overall attainment}

A statistical analysis of the predicted Attainment 8 and Actual Attainment 8 scores show that the attainment of the research group is significantly different to that of the comparison group. Whilst neither group achieved the overall expected attainment, the research group still did much better, with attainment just under the expected, with an average "gain" of minus 0.23 (calculated by subtracting each student's predicted Attainment 8 from their actual Attainment 8 score). This is in contrast to the comparison group which had an average attainment gain score of minus 13.88 meaning that this group were almost 14 points below their expected score compared to the research group who were very nearly meeting expectations. In the overall context of the school, in terms of educational attainment, this is an important gain. An independent samples $t$ test on the gain score shows the difference between the two groups is statistically significant at the 0.01 level suggesting that there has been a significant gain in the overall attainment for the research group: $t,(18),=2.96, p<.01$

Table 2 - Attainment 8 overall gain at GCSE here

\section{Attainment in English, Maths and Science}

An independent samples $t$ test also demonstrated a highly statistically significant gain for the research group in English. There were marginal gains in maths but gains that were still considered statistically significant. In science, the research group made a greater overall average gain than the comparison group. However, the difference between the research and control groups for science was not statistically significant, so should be interpreted cautiously

Table 3 - Gains for English, Maths and Science GCSE here

Given the focus on communication and the use of maths based skills to tackle some of the outdoors activities, such as raft building, the GCSE results are encouraging. Within the 
context of challenge in the case study school, and the school's overall attainment at GCSE, the attainment even more so.

\title{
2. What is the impact of residential experiences on students' perception of their self- efficacy in school?
}

\begin{abstract}
Almost all the students were unequivocal in describing themselves as 'changed' as the result of their experiences. Most students explained this in their own words, directly attributing their sense of change as being the result of their residential experiences; how these had made them feel more confident, particularly with respect to try new things and speaking to new people:
\end{abstract}

The increased sense of efficacy and confidence gained from the outdoor activities expressed was seen by students' as translating directly to the classroom. Primarily, this was expressed in terms of classroom engagement and school work but, more importantly, improvement in grades awarded by teachers for all but two students. In explaining this, students were very clear in linking back to specific experiences:

[Describing the night forest walk]I was very nervous because I never done it before... being in the woods, and it was quite, like, it was dark, and it made me really nervous because I am never usually out that late, it's kinda scary!...I wasn't gonna bother, you know, not try because I was too scared. But I did it and I felt really good about myself!... and it's made me feel more brave in class...to put my hand up and answer questions...more confident in lessons and in general...I think I am doing better than I was before because I am more confident sort of thing and I realised that it helps, having confidence in class (Alice, girl)

I concentrate more in class and my grades are definitely going up...I get easily distracted... but some of the activities we had to do we really had to concentrate on and I think that has helped me concentrate in class, to concentrate on one task rather than let my mind wander... and now my science grades are gone up and I feel more confident speaking and listening in English as well... in science I was getting Us and Ds but now I am getting Bs! (Alan, boy) 
These examples illustrate the relevance of taking risks and moving outside that with which students are familiar. Transferring these skills into school could be considered as relating to Bandura's (1995) 'Mastery' experiences; whereby students experience a sense of achievement and efficacy as a result of perseverance and effort and, to a degree, an element of bravery and risk taking on their part.

Orlando describes his previous sense of embarrassment about trying to get involved in class, fearing that 'people would laugh at me and stuff like that, for trying to be smart'. His experiences through the outdoor residential visits had made him less self-conscious though:

I am more confident to speak to people instead of just sitting there doing nothing...I put my hand up in lesson now, and actually answer the question...I gave a speech to 400 parents, it made me feel good because I actually achieved something...I couldn't imagine doing this two years ago or even last year; I couldn't have imagined myself still in this school [it's made me] not take negative criticism on board...so long as I'm doing good and I know that I am doing good, [that's all that matters] ...I'm predicted $C$ to $A$ in almost every lesson now, err, but I actually think I can do more, I can get $A *$ and A grades

For Orlando much more positive relationships with his family were also a consequence, and an important one that resulted in them spending more time together, a 'wall of achievement' at home that marks his many new accomplishments in school, such as $100 \%$ attendance certificates as well as an increase in school grades, has had a ripple effect, in that he is now sought out by teachers to help with various events.

Orlando is not the only one to believe that the outdoor experiences have had a positive impact on his general attitudes and subsequent confidence in school. Three other students talked of their improved relationships, particularly at home. As Alice, who rarely went out, notes ' $m y$ 
mum says I never used to talk at home and now I never stop [laughs] ...she likes that I go out with friends now too...that I am getting some independence’.

Some of the students attribute their growing sense of self efficacy to multiple factors but being part of a stable research cohort, including students they would not usually mix with was clearly important. Thus the cohort effect on friendship networks emerged as an interesting finding:

I made more friends.... I became... more friendly there like... when I'm at school I'm more ...I stay in my own group, but I was more open to being with other people that I wouldn't normally hang around with in school" (Tom, boy)

I made new friends, we're really good friends now...three of them...they're all looking after me now because I normally get bullied at school... [and so I feel happier at school] ...because I know that someone's on my side now if I'm feeling down" (Alice, girl)

Whilst for some students it was simply being with other students on the residential trips that has resulted in the development of new relationships, others attributed it as the consequence of, as Waite (2003) notes, having to work together with others; building a raft or night walking, for example. These shared experiences had created important bonds of trust and networks that continued into school but had also fostered a confidence to speak to and make friends with others:

I am very shy but now you, just like, have more conversations with people you never used to talk with, different kinds of people, and you have, like, a lot to talk about (Alice, girl) 
For Steven who described himself as solitary, the team working experiences offered by the outdoor activities had prompted recognition 'that being friendly to people gets you a reward back.'

\section{Discussion}

The results of this small scale study suggest that the outdoor residential experiences students participated in had an important influence on the levels of self-efficacy students felt they had. Whether real or imagined, that students felt more confident was significant and their selfefficacy and confidence appeared to directly impact on their sense of self in positive ways within school, particularly in relation to how they saw themselves as learners. Whilst the effect varied between students, and was more influential in some areas than in others, that students were able to articulate positive changes and changes directly connected these to their experiences and their improved sense of self confidence is important.

From this research we infer that it was the repeated nature of the visits that appeared central to the impact we report, in that it allowed time to embed the positive outcomes of the experiences. Whilst one off visits can undoubtedly offer positive outcomes, embedding the learning over time both deepens and reinforces the learning. It was interesting to also note how the activities undertaken by students were seen by them as directly translating back into the classroom, in terms of promoting changes in attitudes, confidence and behaviour as research suggests it does (Hirch et al 2007; Stanford et al 2006; Wikeley et al 2000). Not only did students feel more confident about their own learning, classroom engagement and relationships, they expressed a far greater sense of efficacy in terms of their future potential to achieve goals and ambitions, with effort, in the future. It could be argued then that the 
outdoor opportunities in this study, which included elements of risk taking, could be considered as the 'Mastery' experiences that Bandura (1995) refers to. Overcoming fear as well as achieving success - although not easy success - can be seen to have promoted a sense of efficacy that he argues the 'Mastery' experience promoted.

Strongly connected to the outdoor experiences was the dominant effect of being part of a cohort. The repeated nature of the visits, enabling the embedding and then strengthening of the development of skills, and with the same group of students, proved to be a powerfully influential enabler, which facilitated the development of extended social networks of support and friendship that fed back into school. Opportunities to mix with 'different' students promoted confidence to mix and communicate with new people as well as make new friends. The residential experiences, in this instance, had clearly facilitated an opportunity to bridge social networks as Waite (2013) notes. This research suggests that it is trust that is of importance and relevant to the development of social networks. Spending time interacting in a less formal way offered students an opportunity to connect across social space, whilst the repeated visits within the cohort enable these connections to strengthen into much stronger bonds. The evidence suggests that these positive relationships then continue within school.

However, perhaps the more significant impact of the outdoor experiences relates to students' perceptions of the influences these have had on their attainment in school and grades; all students discuss making substantial progress. This perception then translated into actual success in their final year 11 exams. This is arguably perhaps the key point; that when students began to believe they were making progress they were. Self-identity within education is, as Fuller $(2009 ; 2013)$ notes, key to educational attitudes and aspirations. 
Identifying confidently within education promotes agency and a greater sense of efficacy which is strongly linked to engagement. Whilst it could be contested that the perceived positive impacts on grades and self-confidence are a direct consequence of the outdoor experiences and instead are the outcome of the attention that is inherent in research of this type - i.e. the Hawthorne effect. However whether a student engaged more readily with the research, because of their understanding of the purposes of the research, or not, this does not diminish the value of those experiences. Arguably, as students unequivocally attribute the effects of particular activities - the group work and the challenges of overcoming fear for example - as directly influential in their learning, then this in itself is a powerful argument to affirm the value of the residential outdoor experiences. Teachers' attitudes to students may also be an important factor but was not part of this research.

It is clear that the outdoor residential experiences have had a positive influence on the students included in this research. Whilst the residential aspect was not directly explored it is highly likely that it was important to the development of relationships that seem central to the experiences. This is because residentials allow the affordance of time, in a less formal space. The 'repeatedness' of the visits as well as the cohort effect appears to also be just as important as the positive benefits of the activities themselves. Students' perceptions clearly expressed a link between these and their confidence and thus these experiences can be argued to have real educational value. The examination results also demonstrate that there is a more explicit educational value for schools, and one that suggests much greater promise if outdoor residential programmes of activity can make much more explicit connections between the residential activities and the school curriculum. For example, navigating the low ropes or deciding how long the poles need to be when building a raft was clearly making use of 
mathematical knowledge and skills. Signposting this to students would be very valuable, highlighting the relevance of what they were learning in school to everyday life, for example.

Previous research suggests that there is a lack of evidence on the ways that residential experiences translate back into the classroom. The findings from this study suggest that they can be clearly linked to students' perceptions of increased confidence, positive engagement and improved attainment. This offers support to the view that students are indeed reflective and so are able to re-negotiate their educational identity, as Fuller (2009) notes, and therefore, able to re-define and re-negotiate their educational outcomes. Thus these types of activities can be seen as 'enabling'. Whilst there are many ways that students can be supported to develop their confidence and sense of efficacy as well as residential opportunities and outdoor experiences, for example, mentoring, sports, drama etc., these experiences can be particularly powerful when they become the only exposure to a different context, space and place that some socially disadvantaged children will have.

\section{Conclusion}

Given the international involvement in the broader realm of outdoor learning, it is hoped that this research contributes in an important way to our understanding in this area. This research also raises interesting points for consideration within both policy and practice and poses the question as to whether the classroom should be the only primary site of learning? It also offers evidence to support the value of learning side of the classroom, by highlighting how these types of experiences were useful in developing positive outcomes within school and exam and attainment outcomes. For some students who are underachieving, the classroom 
can become a space that reinforces negative messages connected to learner identity. Thus moving outside the traditional learning environment may be of particular relevance when considering the educational attainment of students from poorer socio-economic backgrounds and pertinent for practitioners who seek ways to promote attainment via Pupil Premium funding. As interventions thus far have done little to address the educational gaps between the socially advantaged and disadvantaged, outdoor experiences do appear to offer an interesting means to tackle some of the factors that may contribute to this gap.

\section{References}

Bandura, A. 1995. Exercise of personal and collective efficacy in changing societies, in SelfEfficacy in Changing Societies, Bandura, A., (Editor), Cambridge University Press.

Bandura, A.1994. Self-efficacy. In V. S. Ramachaudran (Editor), "Encyclopaedia of Human Behavior”,4. New York: Academic Press, pp. 71-81

Beck, U. 1992. Risk Society: Towards a New Modernity, London, Thousand Oaks, New Delhi, Sage Publications.

Bensten, P., Mygind, E. and Randrup, T. 2009. Towards an understanding of udeskole: education outside the classroom in a Danish context, "Education” 3 - 13, Vol. 37, No. 1, pp. 29- 44

Berger, P. and Luckmann, T. 1966. The Social Construction of Reality: A Treatise in the Sociology of Knowledge, USA: Penguin.

Boudon, R. 1974. Education, Opportunity, and Social Inequality: Changing Prospects in Western Society. John Wiley and Sons

Carter-Wall , C. and Whitefield, G. 2012. The role of aspirations, attitudes and behaviour in closing the educational attainment gap. The Joseph Rowntree Foundation. 
Christie, B. Higgins, P. and McLaughlin. 2014. 'Did you enjoy your holiday?' Can residential outdoor learning benefit mainstream schooling?, "Journal of Adventure Education and Outdoor Learning”. Vol. 14, Issue 1, pp. 1-23

Conlon, G. and Patrignan, P. 2011. The returns to higher education qualifications. Business Innovation and Skills

Croll, P. J. Attwood, G., Fuller, C. L. and Last, K. 2008. The Structure and implications of children's attitudes to school. "British Journal of Educational Studies”, 56 (4). pp. 382399. ISSN 1467-8527

Croll, P. Attwood, G. and Fuller, C. 2010. Children's lives, children's futures: A study of children starting secondary school. Continuum Studies in Educational Research . Continuum, London, . pp218.

Cummings, C. Laing, K. Law, J.; McLaughlin, J, Papps, I.; Todd, L. and Woolner, P. 2012. Can Changing Aspirations and Attitudes Impact on Educational Attainment? A Review of Interventions. The Joseph Rowntree Foundation.

Dillon, J. 2004. Evidence of outdoor learning: evidence from the UK and elsewhere. "School Science Review”. 87: 320

DfEa. 2015. Progress 8 school performance measures. https://www.gov.uk/government/uploads/system/uploads/attachment_data/file/456438/ Progress_8_school_performance_measure_2015_updated_August_2015.pdf) (accessed November 2015)

DfEb. 2015. Summer 2015 GCSE Results. https://www.gov.uk/government/news/summer2015-gcse-results-a-brief-explanation (accessed January 2016)

DfE. 2011. Test and Examination Point Scores used in the 2011 School and College Performancetables. file:///C:/Users/ess06clf/Downloads/Gov_GCSE_PointsScoreAllocation2011.pdf (accessed November 2015)

Education and Skills Select Committee Enquiry. 2005. Education Outside of the Classroom, http://www.publications.parliament.uk/pa/cm200405/cmselect/cmeduski/120/12005.htm 
Fiennes, C., Oliver, E., Dickson, K., Escobar, D., Romans, A and Oliver, S. 2015. The Existing Evidence Base about the Value of Outdoor Learning. Giving Evidence: http://www.outdoorlearning.org/Portals/0/IOL\%20Documents/Blagrave\%20Report/outdoor-learninggiving-evidence-revised-final-report-nov-2015-etc-v21.pdf (accessed April 2016)

Fuller, C. L. 2009. Sociology, Gender and Educational Aspirations: Girls and their Ambitions. Continuum, New York. pp201

Fuller, C. and MacFadyen, T. 2012. 'What with your grades?': Students motivation for and experience of vocational courses in further education. "Journal of Vocational Education and Training”, 64 (1). pp. 87-101.

Fuller, C. 2014. Social capital and the role of trust in aspirations for higher education. “Educational Review”, 66 (2). pp. 131-147

Furnee, C., Groot, W., and Maassen van der Brink, H. 2008. The Health Effects of Education: a Meta-Analysis, “European Journal of Public Health”. Vol. 18, No. 4. 417-421

Goldthorpe, J.H. 1996. Class Analysis and the Re-orientation of Class Theory: the Case of Persisting Differentials in Educational Attainment*, "British Journal of Sociology”. Vol. 47.Issue 3. (Sept.) pp. 481-505.

Goldthorpe, J.H., and Breen, R. 2000. Explaining Educational Differentials: Towards a Formal Rational Action Theory in On Sociology: Numbers, Narratives, and the Integration of Research and Theory. Oxford University Press.

Goodman, A and Gregg, P. 2010. Poorer Children's educational attainment: How important are attitudes and behaviour. Joseph Rowntree Foundation

Gutman, L. and Schoon, I. 2012. Correlates and consequences of uncertainty in career aspirations : gender differences among adolescents in England. "Journal of Vocational Behavior”. 80 (3), pp. 608-618. 
Hattie, J.Marsh, H.W. Neill, J.T. and Richards, G.E. 1997. Adventure Education and Outward Bound: Out-of-Class Experiences that make a Lasting Difference, "Review of Educational Research”. Vol. 67, No 1 (Spring) pp. 43 - 87.

Hattie, J. 2015. The Hattie Reports: Is Policy on School Improvement Correctly Aligned?, CSN Policy Briefing, http://www.lgiu.org.uk/wp-content/uploads/2015/08/The-Hattie-

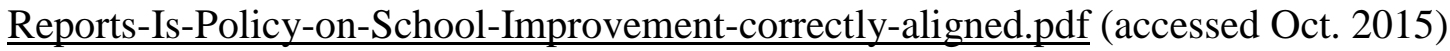

Hirch, D. 2007. Experiences of poverty and educational disadvantage: reviewing the evidence. Joseph Rowntree Foundation

Hodkinson, P. 2008. Understanding career decision making and progression: careership revisited. John Killeen Memorial Lecture, London.

Kerr, K. and West, M. 2010. Social Inequality: can schools narrow the gap?. “Insight2”.British Educational Research Association

Machin, S., Marie, O. and Vujic, S. 2010. The Crime reducing effect of education. Centre for Economic Performance. discussion paper 979

National Children's Bureau. 2013. Greater Expectations: Raising aspirations for our children. London: NCB.

OECD. 2012. How does education affect employment rates?, Education at a Glance 2012: Highlights. OECD Publishing.

OfSTED. 2004. Outdoor Education: Aspects of Good Practice. HMI

Office for National Statistics,http://www.statistics.gov.uk/hub/children-educationskills/index.html (accessed 2012)

Paton, K. 2007. Conceptualising 'Choice'; A review of the theoretical literature, ESRC NonParticipation in HE Project Series. Working Paper 5 
Paul Hamlyn Foundation. 2014. 'What makes a 'Brilliant Residential?' Learning Away's Second Interim Evaluation Report; a Summary, http://learningaway.org.uk/wpcontent/uploads/Learning-Away-Interim-Evaluation-Summary-2-_September-2014.pdf (accessed June 2015)

Paul Hamlyn Foundation. 2015. Brilliant Residentials and their Impact on Children, young people and schools: making the case for high-quality residential learning, Learning Away's Final Evaluation Report. http://learningaway.org.uk/wpcontent/uploads/Learning_Away_summary_spreads_small_FINAL-SUMMARY.pdf (accessed October 2015).

Putman, R. 2000. Bowling Alone: The Collapse and Revival of American Community. New York: London, Simon and Schuster

Rickinson, M., Dillon, J., Teamey, K., Morris, M., Choi, M. Y., Sanders, D. and Benefield, P. 2004. A review of research on outdoor learning. Preston Montford, Shropshire: Field Studies Council

Sabates, R. Harris, A.L., and Staff, j. 2011. Ambition gone awry: the long-term socioeconomic consequences of misaligned and uncertain ambitions in adolescence, “Social Science Quarterly”. 92(4), p959-77.

Standford, R.Armoura, K., and Warnington, P. 2006. Re-engaging disaffected youth through physical activities programmes, "British Educational Research Journal”. Vol. 32, No. 2, pp 251-271

Teenage Pregnancy Associates. 2011. Teenage Pregnancy: The Evidence. http://teenagepregnancyassociates.co.uk/tpa-evidence.pdf (accessed 2015)

Waite, S. 2010. Losing our way declining outdoor opportunities or learning for children aged between 2 and 11, “Journal of Adventure Education and Outdoor Learning”. 10 (2) pp. $111-126$

Waite, S. 2013. 'Knowing your place in the world': how place and culture support and obstruct educational aims, “Cambridge Journal of Education”. 43:4, pp 413-433 
Wikeley, F. Bullock, K.Muschamp, Y., and Ridge, T. 2000. Educational Relationships outside school: why access is important. The Joseph Rowntree Foundation

Williams, R. 2013. Woven into the fabric of experience; residential adventure education and complexity. "Journal of Adventure Education and Outdoor Learning”, Vol. 13. Issue 2, pp. $107-124$

\begin{tabular}{|l|l|l|}
\hline & Research Group & Control Group \\
\hline Gender & $\begin{array}{l}\text { 9 Male } \\
3 \text { Female }\end{array}$ & $\begin{array}{l}\text { 9 Male } \\
3 \text { Female }\end{array}$ \\
\hline PP & 8 & 5 \\
\hline ESL & 3 & 3 \\
\hline SES & Manual & Manual \\
\hline
\end{tabular}

Table 1 - Information on sample

\begin{tabular}{|l|l|}
\hline Group & Gain \\
\hline Research group & -0.23 \\
\hline Control group & -13.88 \\
\hline
\end{tabular}

Table 2 - Attainment 8 overall gain at GCSE

\begin{tabular}{|l|l|l|l|}
\hline Group & English & Math & Science \\
\hline Research group & -1.20 & -3.60 & -13.20 \\
\hline Control group & -10.20 & -10.20 & -24.20 \\
\hline Independent t test & $t,(18),=3.84, p<.001$ & $t,(18),=2.02, p<=0.058$ & $t,(18),=1.37, p=0.18$ \\
\hline
\end{tabular}


Table 3 - Gains for English, Maths and Science GCSE 